\title{
An Investigation of Thermal Characteristics of a Sintered-Wick Heat Pipe with Double Heat Sources
}

\author{
Nattawut Tharawadee, Pradit Terdtoon and Niti Kammuang-lue \\ Department of Mechanical Engineering, Faculty of Engineering, Chiang Mai University, Thailand
}

Received 2013-06-05, Revised 2013-08-09; Accepted 2013-08-20

\begin{abstract}
Heat pipes have been used extensively in the electronic industry for decades especially in laptop computers. For cost-effectiveness, a single heat pipe is designed to simultaneously transfer heat from both the Central Processing Unit (CPU) and the Graphics Processing Unit (GPU) inside the main board to the heat sink. This causes the efficiency of the heat pipe to change without any theoretical prediction. In this research, thermal performance of a sintered-wick heat pipe with double heat sources has been experimentally and numerically investigated by utilizing the Finite Element Method (FEM). The focus being the effect that the distance between the two heat sources and also the power input pattern (heat source\#1 (HT1): Heat source\#2(HT2) has on temperature and thermal resistance of the heat pipe. The first heat source (HT1) was located at one end and the heat sink was located at another end of the heat pipe, while another heat source (HT2) was placed between HT1 and a heat sink. The ratios of heat input power were controlled at $10 \mathrm{~W}: 10 \mathrm{~W}, 20 \mathrm{~W}: 10 \mathrm{~W}$ and $30 \mathrm{~W}: 10 \mathrm{~W}$. Two copper blocks $(15 \times 15 \mathrm{~mm})$ were used as heat sources for the evaporator section $(\mathrm{Le} 1, \mathrm{Le} 2)$ to electrically supply heat to the bottom half of the heat pipe. A mathematical model using the Finite Element Method (FEM) was established to calculate temperature and thermal resistance. The speed of the cooling fan was adjusted to maintain constant operating temperature at the adiabatic section throughout the tests. The operating temperature was controlled at $60 \pm 3^{\circ} \mathrm{C}$. It was noted that, when distance between the heat sources was increased from $0 \mathrm{~mm}$ to $75 \mathrm{~mm}$, thermal resistance slightly decreased from $0.589-0.53^{\circ} \mathrm{C} / \mathrm{W}$ respectively. Heat source 2, therefore, should be placed as close as possible to the condenser section. Both heat sources should have a distance between them of at least $12 \mathrm{~mm}$, which minimizes heat accumulation. When the power input of HT1 was increased from $10 \mathrm{~W}$ to $30 \mathrm{~W}$ (HT2 was fixed at $10 \mathrm{~W}$ ), thermal resistance slightly increased from $0.56-0.58^{\circ} \mathrm{C} / \mathrm{W}$. The results from the mathematical model are in good agreement with the experimental data (STD $\pm 2.54 \%$ ). Therefore, from this study, we are able to design an effective heat pipe for double heat source applications which is very useful for the electronic industry. Finally, a guideline and knowledge were obtained for designing a heat pipe with double heat sources.
\end{abstract}

Keywords: Heat Pipe, Porous Media, Finite Element Method, Multiple Heat Source, Thermal Resistance

\section{INTRODUCTION}

At present, new cooling methods suitable for thin, compact structures and high thermal density applications (e.g., laptop computer) are urgently needed. One of such methods is employing a heat pipe as a heat conveyer from a CPU chip to a cooling fan in an electronic circuit to transfer heat by using the principles of evaporation and condensation. This process allows for extremely high heat transfer rates. The porous media (wick) is generally used to draw the working fluid back from the condenser to the evaporator section as shown in Fig. 1. Corresponding Author: Niti Kammuang-lue, Department of Mechanical Engineering, Faculty of Engineering, Chiang Mai University, Thailand 


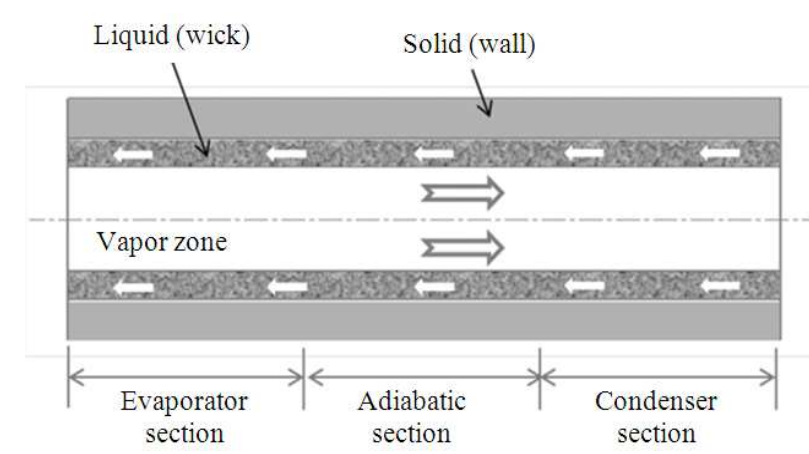

Fig. 1. Working principle of heat pipe

As the wick material has a high capillary force, the liquid therefore flows easier and has low thermal resistance. Therefore the wick material is suitable to be a good heat transfer media. In the same way, the performance of a heat pipe with a sintered grooved wick material was higher than other materials (Kim et al., 2003; Mashiko et al., 2005).

There are various means to study thermal characteristics of a heat pipe. Previously, several approaches to simulate heat pipe operations had been studied regarding vapor flow in a cylindrical heat pipe by utilizing the numerical method (Busse and Prenger, 1984). The effect of liquid-vapor interface in the porous-media of a cylindrical heat pipe using nonDarcian law was investigated and analyzed. The thermal performance of a heat pipe was calculated and predicted by using a developed software tool (Zhu and Vafai, 1999; Maziuk et al., 2001; Vasiliev et al., 2002). Two-dimensional heat transfer and fluid flow in a heat pipe at steady state was numerically simulated using the Finite Element Method (FEM) to calculate velocity, pressure and temperature profile in the bent heat pipe (Thuchayapong et al., 2012). Moreover, the effect of pipe flattening on heat transfer characteristics and the internal phenomena of a sintered-wick heat pipe has been investigated by using three-dimensional Finite Element Method. Recently, heat pipes have been effectively used to cool heat sources from notebook computers. However, there are several units within a notebook computer, such as a Central Processing Unit (CPU) and Graphic Processing Unit (GPU), which act as heat sources and cause temperatures to increase at several points within the computer. So, the heat pipe has been necessarily designed to transfer heat from multiple heat sources inside the circuit board, in order to reduce the number of heat pipes necessary and thus reduce cost. But there still exists a problem regarding transferring heat from more than one heat source within the notebook computer. In addition, there are many numerical modeling research studies done about the distribution of wall and vapor temperature of screen mesh wick heat pipes with two heat sources. The model usually used two dimensional domains for easy calculation. Our assumption is that a three dimensional domain might simulate a heat pipe to be similar to an actual heat pipe. Thus, a heat pipe in three dimensions is needed. However, previous research only studied about heat pipes with a screen mesh wick. Hence, sintered grooved porous media heat pipe is needed for additional study (Chen and Faghri, 1990; Faghri and Buchko, 1991). The previous studies have not reported on the sintered porous media with multiple heat sources.

In this research, we studied the thermal performance of the sintered porous media heat pipe with double heat sources using the Finite Element Method (FEM). The advantage of our model is the ability to analyze characteristics of the same heat pipe configuration with multiple heat sources. We defined a straight-line heating path consisting of one heat sink and two heat sources. The results from the mathematical model and experimental result were determined and compared for a sintered grooved porous media heat pipe with double heat sources. Therefore, from this study, we are able to design an effective heat pipe for a double-heat-source application which is very useful for the electronic industry. Finally, a guideline and knowledge were obtained to design a heat pipe with double heat sources.

\section{MATERIALS AND METHODS}

\subsection{Finite Element Method (FEM)}

In this research, three domains consisting of vapor core, wick and tube wall have been focused on in the mathematical model domains. The conservation of mass equation, momentum and energy were chosen to be the governing equation in order to closely simulate physical phenomena in the heat pipe. In the mathematic model, the working fluid is assumed to be incompressible. It's flow is also assumed to be laminar and steady.

Governing equations in the vapor core were defined as follows.

Continuity Equation 1:

$$
\frac{\partial u_{v}}{\partial x}+\frac{\partial v_{v}}{\partial y}+\frac{\partial w_{v}}{\partial z}=0
$$

Momentum Equation 2-4: 


$$
\begin{aligned}
& 0=-\frac{\partial \mathrm{P}_{\mathrm{v}}}{\partial \mathrm{x}}+2 \mu_{\mathrm{v}} \frac{\partial^{2} \mathrm{u}_{\mathrm{v}}}{\partial \mathrm{x}^{2}}+\mu_{\mathrm{v}}\left(\frac{\partial^{2} \mathrm{u}_{\mathrm{v}}}{\partial \mathrm{y}^{2}}+\frac{\partial^{2} \mathrm{u}_{\mathrm{v}}}{\partial \mathrm{z}^{2}}+\frac{\partial^{2} \mathrm{v}_{\mathrm{v}}}{\partial \mathrm{x} \partial \mathrm{y}}+\frac{\partial^{2} \mathrm{w}_{\mathrm{v}}}{\partial \mathrm{x} \partial \mathrm{z}}\right) \\
& 0=-\frac{\partial \mathrm{P}_{\mathrm{v}}}{\partial \mathrm{y}}+2 \mu_{\mathrm{v}} \frac{\partial^{2} \mathrm{v}_{\mathrm{v}}}{\partial \mathrm{y}^{2}}+\mu_{\mathrm{v}}\left(\frac{\partial^{2} \mathrm{u}_{\mathrm{v}}}{\partial \mathrm{x} \partial \mathrm{y}}+\frac{\partial^{2} \mathrm{v}_{\mathrm{v}}}{\partial \mathrm{x}^{2}}+\frac{\partial^{2} \mathrm{v}_{\mathrm{v}}}{\partial \mathrm{z}^{2}}+\frac{\partial^{2} \mathrm{w}_{\mathrm{v}}}{\partial \mathrm{y} \partial \mathrm{z}}\right) \\
& 0=-\frac{\partial \mathrm{P}_{\mathrm{v}}}{\partial \mathrm{z}}+2 \mu_{\mathrm{v}} \frac{\partial^{2} \mathrm{w}_{\mathrm{v}}}{\partial \mathrm{z}^{2}}+\mu_{\mathrm{v}}\left(\frac{\partial^{2} \mathrm{u}_{\mathrm{v}}}{\partial \mathrm{x} \partial \mathrm{z}}+\frac{\partial^{2} \mathrm{v}_{\mathrm{v}}}{\partial \mathrm{y} \partial \mathrm{z}}+\frac{\partial^{2} \mathrm{w}_{\mathrm{v}}}{\partial \mathrm{x}^{2}}+\frac{\partial^{2} \mathrm{w}_{\mathrm{v}}}{\partial \mathrm{y}^{2}}\right)
\end{aligned}
$$

Energy Equation 5:

$$
\rho_{v} C_{v, v}\left(u_{v} \frac{\partial T_{v}}{\partial x}+v \frac{\partial T_{v}}{\partial y}+w \frac{\partial T_{v}}{\partial z}\right)=k_{v}\left[\frac{\partial^{2} T_{v}}{\partial x^{2}}+\frac{\partial^{2} T_{v}}{\partial y^{2}}+\frac{\partial^{2} T_{v}}{\partial z^{2}}\right] \text { (5) }
$$

Governing equations in the wick and container wall: The energy equation in the wall is the steady heat conduction equation as follows Equation 6:

$$
0=\mathrm{k}_{\text {eff }}\left[\frac{\partial^{2} \mathrm{~T}_{\mathrm{s}}}{\partial \mathrm{x}^{2}}+\frac{\partial^{2} \mathrm{~T}_{\mathrm{s}}}{\partial \mathrm{y}^{2}}+\frac{\partial^{2} \mathrm{~T}_{\mathrm{s}}}{\partial \mathrm{z}^{2}}\right], 0=\mathrm{k}_{\mathrm{s}}\left[\frac{\partial^{2} \mathrm{~T}_{\mathrm{s}}}{\partial \mathrm{x}^{2}}+\frac{\partial^{2} \mathrm{~T}_{\mathrm{s}}}{\partial \mathrm{y}^{2}}+\frac{\partial^{2} \mathrm{~T}_{\mathrm{s}}}{\partial \mathrm{z}^{2}}\right]
$$

After the governing equations were defined, in order to establish the model, we do need to specify boundary conditions. The heat inputs from each heat source $\left(\mathrm{Q}_{\mathrm{HT} 1}\right.$, $\mathrm{Q}_{\mathrm{HT} 2}$ ) were transferred to evaporate working fluid at liquid-vapor interface in each evaporator section. Total heat output $\left(\mathrm{Q}_{\mathrm{HT} 1}+\mathrm{Q}_{\mathrm{HT} 2}\right)$ was released by condensation at the liquid-vapor interface in the condenser section. Then, the average vapor velocity of a heat pipe with double heat sources is given as follows.

Evaporator section Equation 7:

$$
\mathrm{v}_{\mathrm{e}, 1}=\frac{\mathrm{Q}_{\mathrm{HT} 1}}{\rho_{\mathrm{v}} \times \mathrm{W}_{\mathrm{s}} \times \mathrm{L}_{\mathrm{e}, 1} \times \mathrm{h}_{\mathrm{fg}}}, \mathrm{v}_{\mathrm{e}, 2}=\frac{\mathrm{Q}_{\mathrm{HT} 2}}{\rho_{\mathrm{v}} \times \mathrm{W}_{\mathrm{s}} \times \mathrm{L}_{\mathrm{e}, 2} \times \mathrm{h}_{\mathrm{fg}}}
$$

Condenser section Equation 8:

$$
\mathrm{v}_{\mathrm{c}}=\frac{\mathrm{Q}_{\mathrm{HT} 1}+\mathrm{Q}_{\mathrm{HT} 2}}{\rho_{\mathrm{v}} \times \mathrm{W}_{\mathrm{s}} \times \mathrm{L}_{\mathrm{c}} \times \mathrm{h}_{\mathrm{fg}}}
$$

The equation below is used to calculate thermal resistance due to phase change phenomena of the working fluid at the surface between the sintered wick and the vapor core (Jirapol, 2008).

At evaporator section surface Equation 9:

$$
\mathrm{Z}_{\text {surface,evap }}=\frac{\mu_{1} \mathrm{~T}_{\mathrm{v}} \varepsilon}{\rho_{\mathrm{v}} \mathrm{h}_{\mathrm{fg}} \sigma_{1} 2 \pi \mathrm{rL}_{\mathrm{e}}(1-\varepsilon)}
$$

At condenser section surface Equation 10:

$$
Z_{\text {surface, cond }}=\frac{0.335 Q^{1 / 3}}{d_{w i}^{1 / 3} L_{c}^{1 / 3} \phi^{4 / 3}}, \phi=\left[\frac{h_{\mathrm{fg}} k_{1}^{3} \rho_{1}^{3}}{\mu_{1}}\right]^{1 / 4}
$$

The uniform temperature condition $\left(\mathrm{T}_{\mathrm{v}}=\mathrm{T}_{1}\right)$ was assumed at the liquid-vapor interface, in both the evaporator and condenser sections. The temperature at this interface is equal to the saturated temperature of vapor pressure $\left(\mathrm{T}_{\mathrm{v}}=\mathrm{T}_{1} \mathrm{~T}_{\mathrm{sat} @ \mathrm{P} .}\right)$. At both pipe ends, the insulated boundary condition was assumed $\left(\partial \mathrm{T}_{\mathrm{v}} / \partial \mathrm{n}=\right.$ $\left.\partial \mathrm{T}_{1} / \partial \mathrm{n}=\partial \mathrm{T}_{\mathrm{s}} / \partial \mathrm{n}\right)$ and the fluid velocity was equal to zero $\mathrm{u}_{\mathrm{v}}=\mathrm{u}_{\mathrm{l}}=\mathrm{v}_{\mathrm{v}} \mathrm{v}_{\mathrm{l}}=0$. The end of the evaporator section was set as a reference by controlling the temperature.

The referent pressure was also assumed to be equal to the saturated pressure at the operating temperature $\left(\mathrm{P}_{\mathrm{v}}\right.$ $=\mathrm{P}_{\text {sat } @} \mathrm{~T}_{\mathrm{v}}$. At the inner wall of the heat pipe (wick-wall interface), the non-slip boundary condition was assumed $\left(u_{v}=v_{v}=0\right)$ and the following energy balance was at the interface. At the outer wall of the heat pipe, the evaporator section was uniformly heated and the condenser section was cooled by a heat sink with a fan. Then, the boundary condition at the outer wall in the evaporator, the adiabatic and the condenser section can be given by $\mathrm{q}_{\mathrm{in}}=\mathrm{k}_{\mathrm{s}}(\partial \mathrm{T} / \partial \mathrm{n}) \mid$ wall, $(\partial \mathrm{T} / \partial \mathrm{n}) \mid$ wall $=0$ and qout $=\mathrm{k}_{\mathrm{s}}(\partial \mathrm{T} / \partial \mathrm{n}) \mid$ wall. The conservation equations and boundary conditions were solved using the FEM, while matrices were derived from these equations using the standard Galerkin approach. First, the simulation program generated the grids. The pressure and the velocity distributions in the vapor core were then calculated from the equation of continuity and the momentum equations. Next, the temperature distribution in the vapor core was calculated from the energy equation. Finally, the temperature distribution of the wick and the wall of the container were calculated from the energy equation.

\subsection{Experimental Setup}

The experimental setup was used to evaluate the thermal resistance of the sintered grooved porous media heat pipes with two heat sources and to verify the mathematical model as in Fig. 2. The experimental setup consisted of a cooling system, testing platform, power supply and measurement system. The total length of the heat pipe was $200 \mathrm{~mm}$. The cooling system included an adjustable speed fan and heat sink. The cooling length (condenser, Lc) was set at $70.0 \mathrm{~mm}$. The size of each dimension was based on a typical heat pipe used in practical applications. 


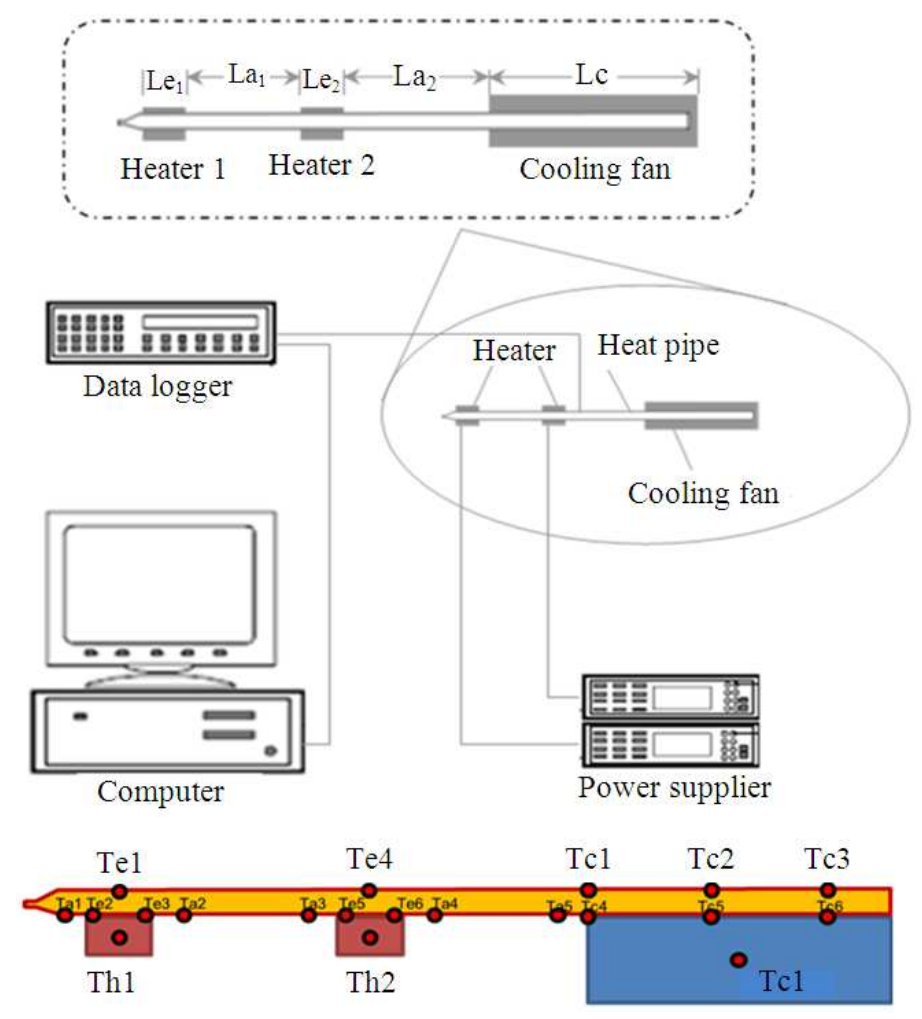

Fig. 2. Schematic of the experimental setup and positions of attached thermocouples

The cooling fan (MINEBEA: 12V DC, 2406KL-04WB56) blew air through the heat sink to remove the heat from the heat pipe by forced convection. The speed of the cooling fan was adjusted in order to maintain the required constant operating temperature at the adiabatic section throughout the tests. The operating temperature was controlled at $60 \pm 3^{\circ} \mathrm{C}$. The two copper blocks $(15$ $\mathrm{mm} \times 15 \mathrm{~mm}$ ) were used as heat sources for the evaporator section (Le1, Le2). A DC electrical current (GW-INSTEK: GPR-7550D) was applied to each heat source at the evaporator section. The power input of HT1 is $10 \mathrm{~W}, 20 \mathrm{~W}$ and $30 \mathrm{~W}$, respectively (HT2 is fixed at $10 \mathrm{~W})$. The heat load and temperatures were acquired using the data logger (BRAINCHILD Data logger: VR18). Type-K thermocouples were attached to monitor the temperature distributions at twenty points as in Fig. 2. Prior to each data acquisition, a 30 -min period of time was allowed for the system to reach its steady state. The temperatures along the heat pipe were measured and recorded when the system reached the steady state. Three experimental data sets were conducted on each process to confirm that the data is reliable and verifiable. Thermal resistance of each case was calculated from the average temperature of the two power inputs. Then, experimental results were compared with the mathematical model.

\section{RESULTS AND DISCUSSION}

\subsection{Effect of Distance between Two Heat Sources on Thermal Resistance}

The temperature profile of a heat pipe with double heat sources of each of the power input patterns is shown in Fig. 3. The power input of each heat source $\left(\mathrm{H}_{\mathrm{T} 1}, \mathrm{H}_{\mathrm{T} 2}\right)$ was set at $20 \mathrm{~W}$. The distances between the two heat sources were $0,25,50$ and $75 \mathrm{~mm}$ respectively. It was found that, when $\mathrm{H}_{\mathrm{T} 1}$ overlapped with $\mathrm{H}_{\mathrm{T} 2}$ (distance $0 \mathrm{~mm}$ ), the temperature of the evaporator $\left(\mathrm{H}_{\mathrm{T} 1}, \mathrm{H}_{\mathrm{T} 2}\right)$ increases to $77.4^{\circ} \mathrm{C}$ due to the heat accumulated from both heat sources. After that, when the distance is 25,50 and $75 \mathrm{~mm}$, the temperature of each evaporator section will decrease to $73.07^{\circ} \mathrm{C}(75$ $\mathrm{mm})$. Heat source 2 should be placed as close as possible to the condenser section. Heat was transferred to the condenser section easily since the distance between $\mathrm{H}_{\mathrm{T} 2}$ and the condenser is shorter. 
Nattawut Tharawadee et al. / American Journal of Applied Sciences 10 (9): 1077-1086, 2013

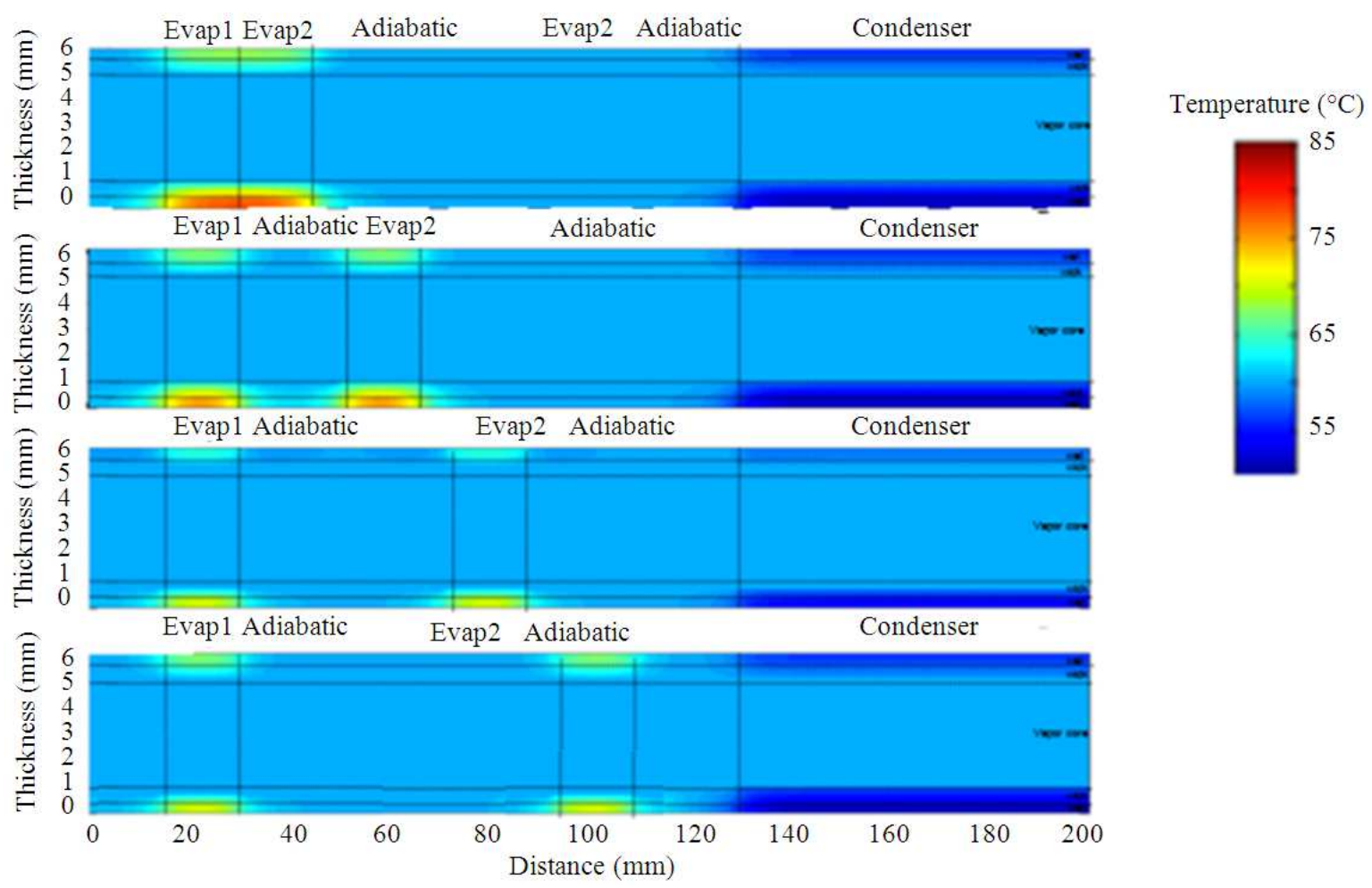

Fig. 3. Effect of distance between two heat source on thermal resistance (temperature distributions)

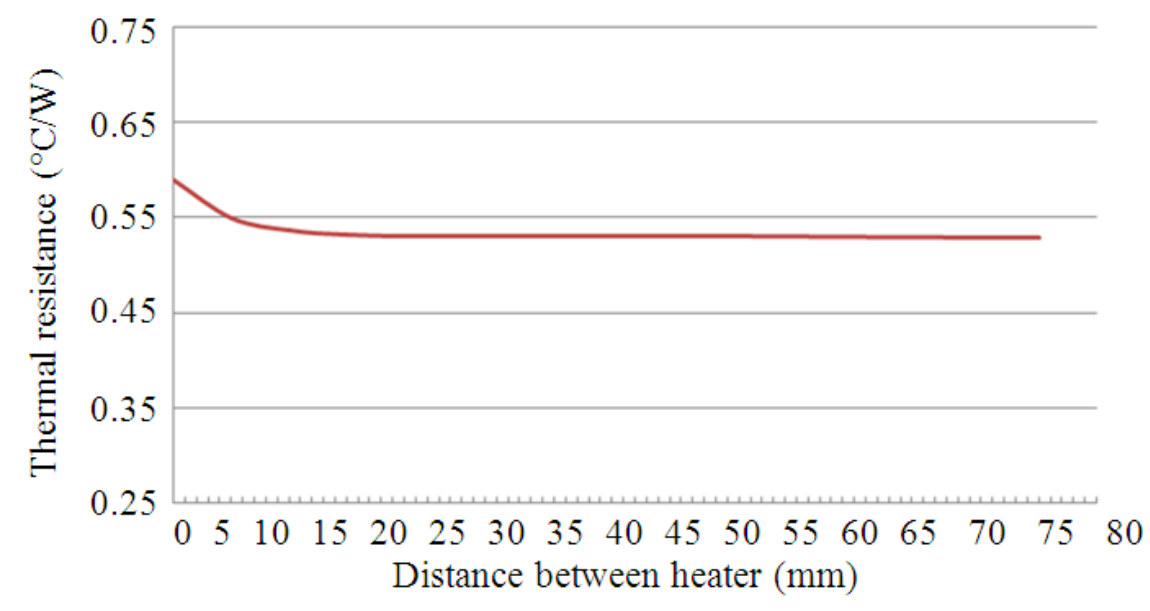

Fig. 4. Effect of distance between two heat source on thermal resistance (thermal resistance)

As mentioned above, thermal resistance was calculated from the equation $\mathrm{Z}_{\text {total }}=\left(\left(\left(\mathrm{T}_{\mathrm{HT} 1}+\mathrm{T}_{\mathrm{HT} 2}\right) / 2\right)-\mathrm{T}_{\mathrm{c}}\right) / \mathrm{Q}_{\text {total }}$. From Fig. 4, the $x$-axis is the distance between the heat source and the $y$-axis is the thermal resistance. It was noted that, when distance between the heat sources were increased from $0 \mathrm{~mm}$ to $75 \mathrm{~mm}$, thermal resistance slightly decreased from $0.589-0.53^{\circ} \mathrm{C} / \mathrm{W}$ respectively as in Fig. 4. This revealed that heat source 2 should be placed as close as possible to the condenser section. Both heat sources should have a distance between them of at least $12 \mathrm{~mm}$, which has the effect of minimizing the heat accumulating from the heat sources as shown in Fig. 4. 

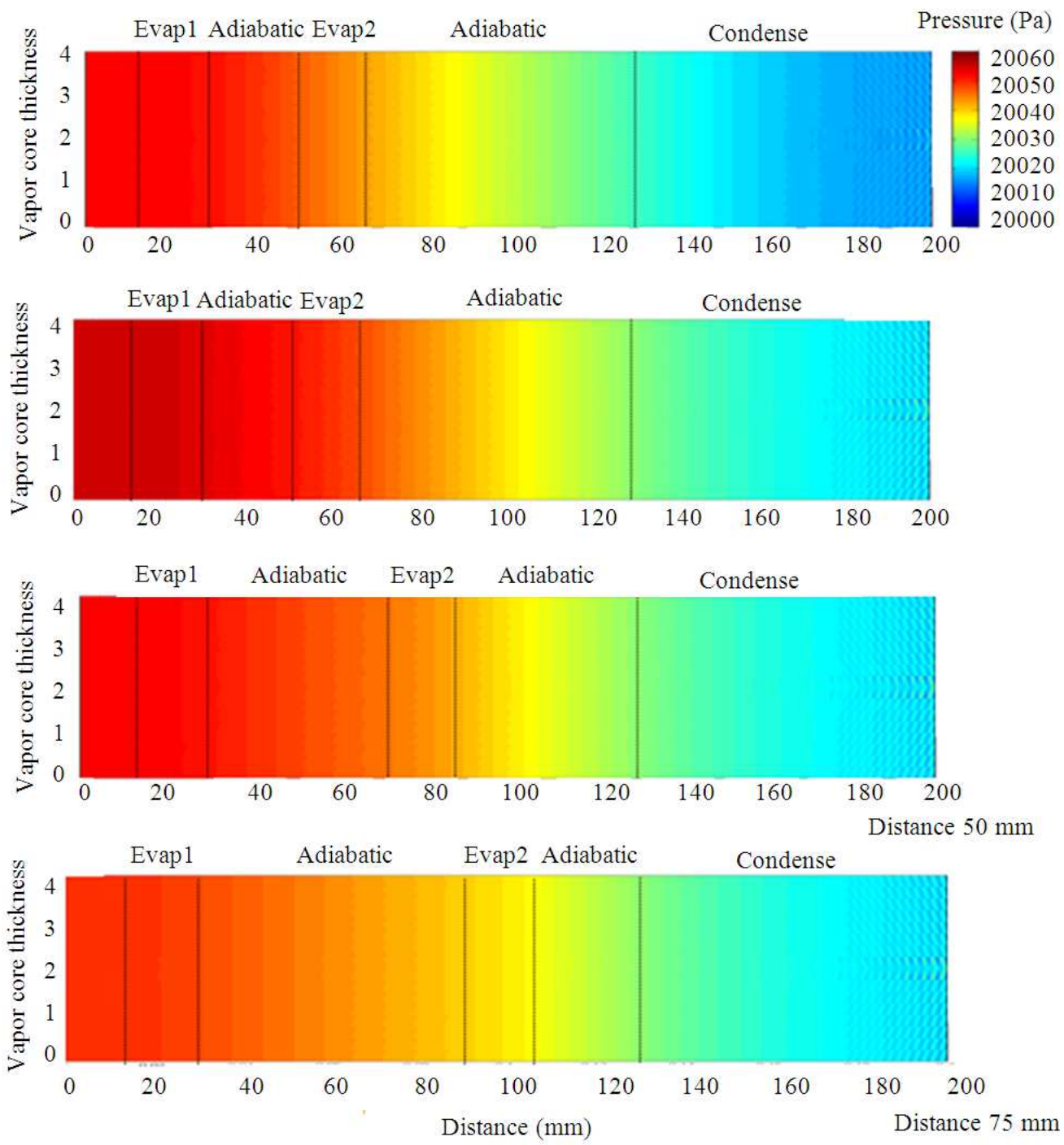

Fig. 5. Effect of distance between two heat sources on thermal resistance (vapor pressure profile)

Moreover, Fig. 5 clarifies the effect that the distance between the two heat sources has on vapor pressure drop of the heat pipe. It was found that, the highest pressure occurred at the end of the heat pipe. The pressure then gradually decreased at the adiabatic section and condenser section. It can be noted that, the heat transfers from the end of the heat pipe (high temperature) to the condenser section (low temperature). This pressure profile can describe the physical phenomena of the working fluid inside the heat pipe. When the working fluid is heated at the evaporator section, it will evaporate to vapor and pressure increases. The working fluid (vapor phase) will flow through the adiabatic section and to the condenser section. The pressure will decrease at the end of the condenser section due to the fact that the vapor is condensed to liquid. The vapor pressure profile inside the vapor core of the heat pipe with two heat sources was similar to that of the heat pipe with one heat source.

It can be seen that when the distance between the heat sources is increased from 0 to $75 \mathrm{~mm}$, the vapor pressure drop will significantly decrease from $35.9 \mathrm{~Pa}$ to $29.01 \mathrm{~Pa}$. It can be concluded that, when the second heat source overlapped with the first heat source, evaporator temperature will significantly increase from $73.07-77.4^{\circ} \mathrm{C}$. 
Nattawut Tharawadee et al. / American Journal of Applied Sciences 10 (9): 1077-1086, 2013

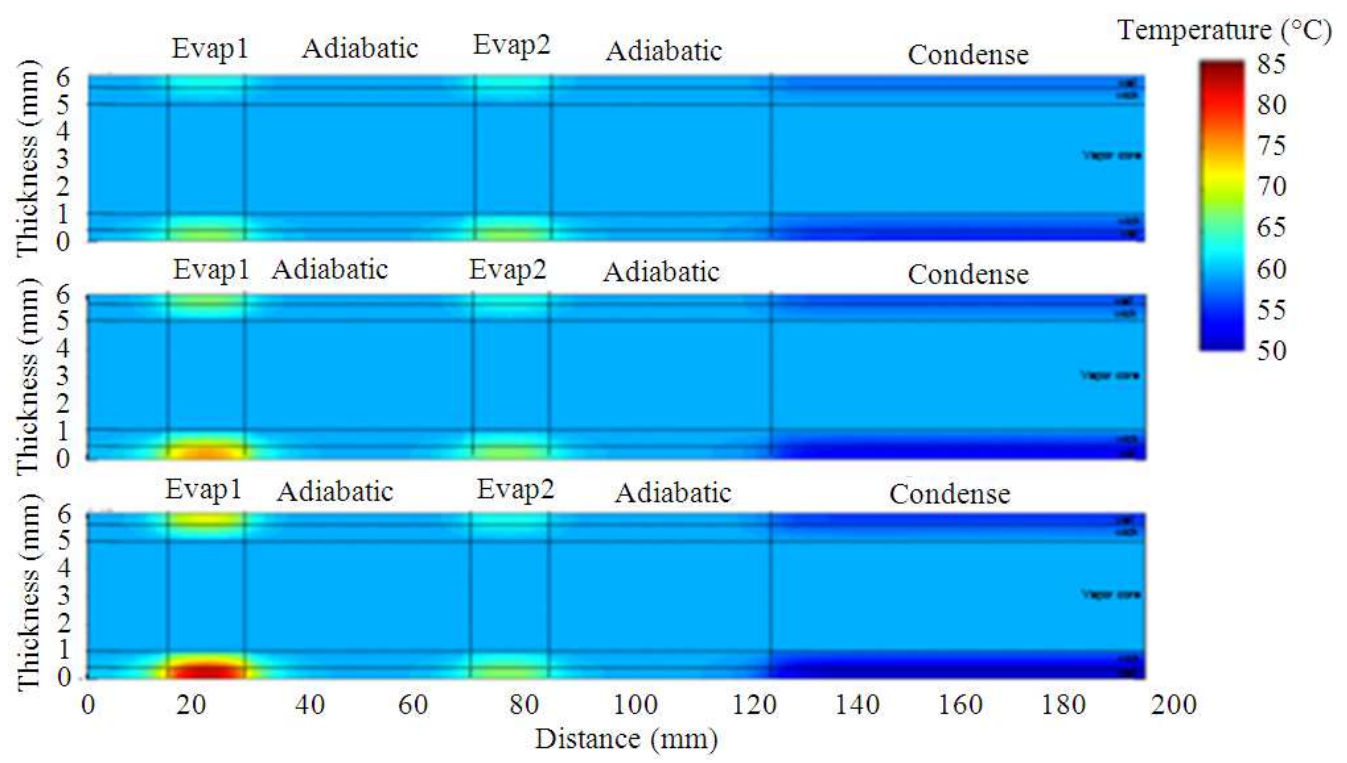

Fig. 6. Effect of power input patterns on thermal resistance (temperature distributions)

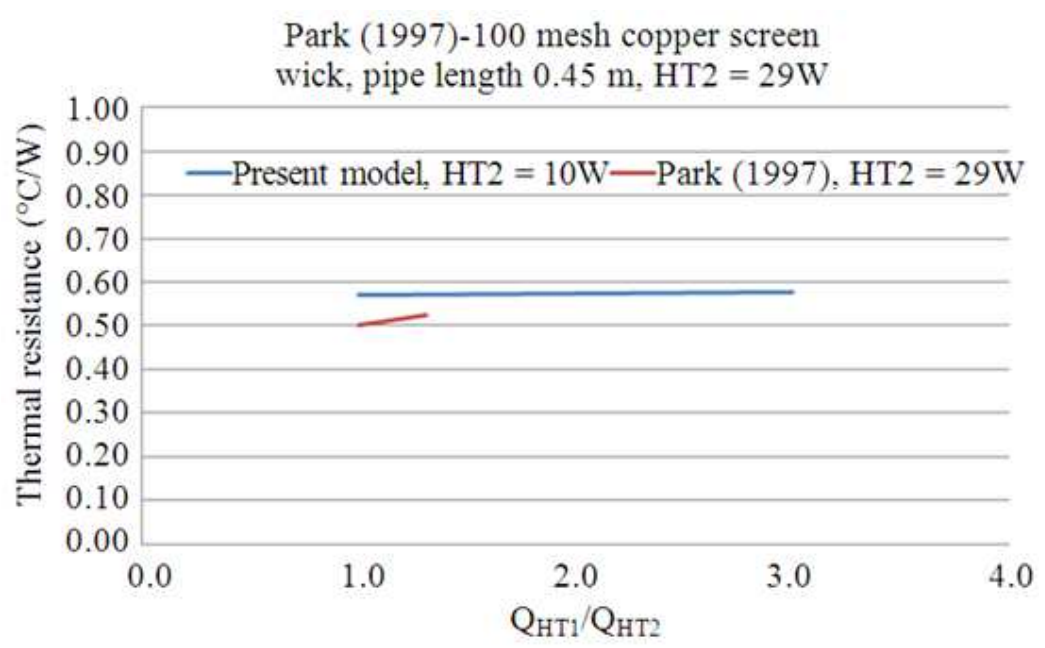

Fig. 7. Effect of power input patterns on thermal resistance (thermal resistance)

Thermal resistance will slightly decrease from 0.589 $0.53^{\circ} \mathrm{C} / \mathrm{W}$ when increasing the distance between the heat sources to $12 \mathrm{~mm}$. Then, when the distance was increased more than $12 \mathrm{~mm}$, the thermal resistance was quite constant at $0.53^{\circ} \mathrm{C} / \mathrm{W}$. It can be seen that the vapor pressure drop decreased when the distance between each heat sources were increased. When the heat source was placed closer to the condenser section, the heat transferred more easily to the condenser section. It causes the evaporator temperature to decrease.

\subsection{Effect of Power Input Patterns on Thermal Resistance}

The temperature profile of the heat pipe with double heat sources with each power input pattern is shown in Fig. 6. The power inputs of HT1 were $10 \mathrm{~W}, 20 \mathrm{~W}$ and $30 \mathrm{~W}$ (HT2 is fixed at $10 \mathrm{~W}$, due to a limit of maximum total heat transfer of the heat pipe). It can be seen that, when the power input of HT1 was increased from $10 \mathrm{~W}$ to $30 \mathrm{~W}$, the highest temperature significantly increased from $67.45-82.33^{\circ} \mathrm{C}$ at the evaporator section. 

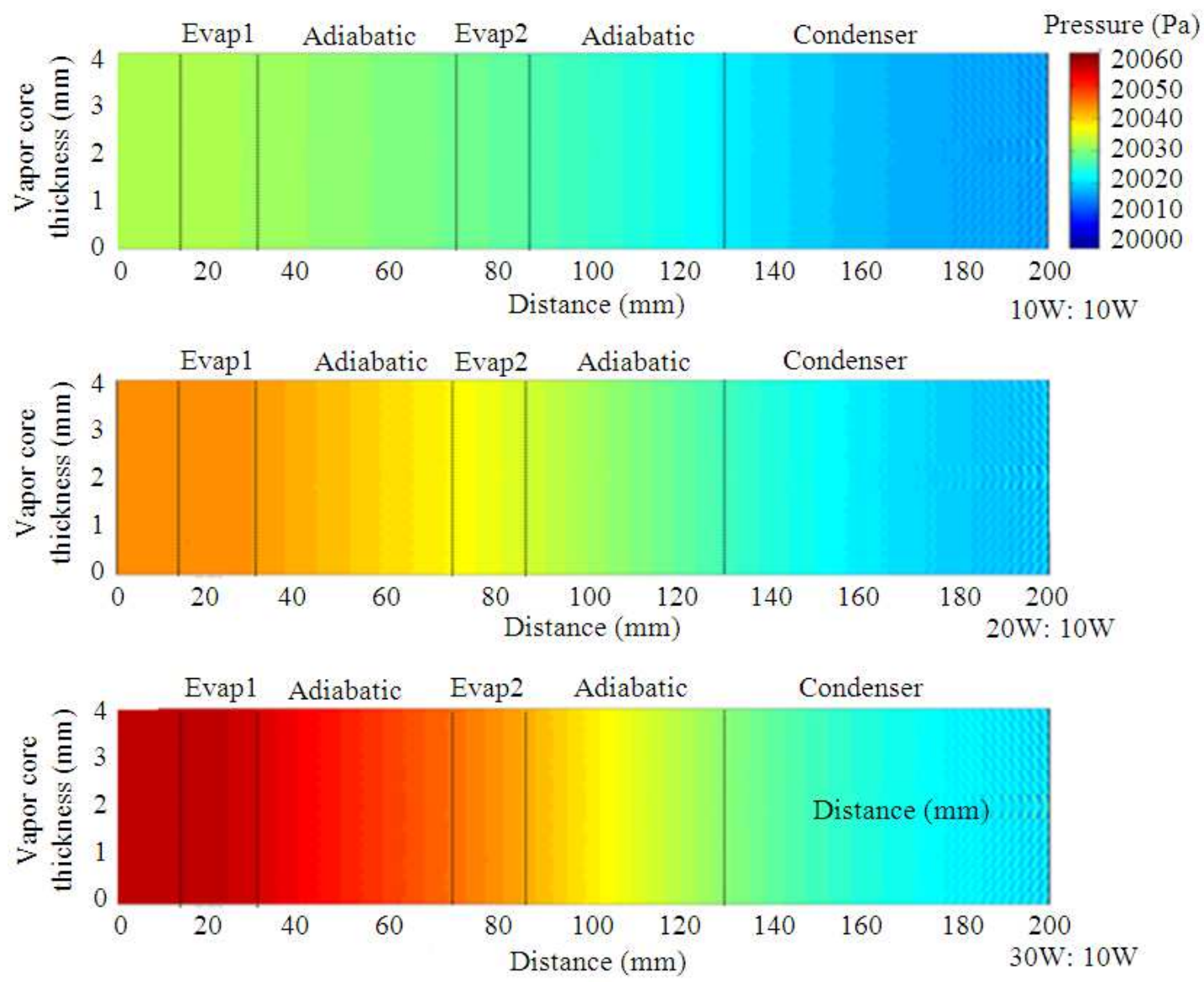

Fig. 8. Effect of power input patterns on thermal resistance (vapor pressure profile)

From Fig. 7, the X-axis is the ratio between QHT1 and QHT2 and the y-axis is the thermal resistance. It was noted that, when the power input of HT1 was increased from $10 \mathrm{~W}$ to $30 \mathrm{~W}$, the temperature of HT1 was increased and thermal resistance slightly increased from $0.56^{\circ} \mathrm{C} / \mathrm{W}$ to $0.58^{\circ} \mathrm{C} / \mathrm{W}$. Park (1997) investigated thermal resistance of s screen mesh wick heat pipe with two heat sources. It reveals that, increasing HT1 from 29 to $38 \mathrm{~W}$ (heat source2 fixed to $29 \mathrm{~W}$ ) influenced thermal resistance slightly by increasing it from 0.50 to $0.522^{\circ} \mathrm{C} / \mathrm{W}$. The trend of thermal resistance from this experiment which slightly decreased agreed with Park (1997). Moreover, vapor pressure drop was increased from $16.00 \mathrm{~Pa}$ to 28.03 $\mathrm{Pa}$; the performance of the heat pipe was slightly deceased as in Fig. 8.

\subsection{Comparison of Temperature Distribution Obtained From Model and Experimental Data}

To verify the finite element method model, twelve points of temperatures were measured on the outer wall surface of the heat pipe at the evaporator, adiabatic and condenser sections. Then, the temperatures data were compared between experiment and finite element method calculation. From comparison of results, it was found that, the percentages of Standard Deviation (STD) of each power input pattern was about $2.54 \%$ which was an acceptable result as shown in Fig. 9. The predictions of temperatures at the outer wall surface of the heat pipe were in good agreement with the experimental results (STD, 2.54\%). However, the maximum temperature difference was observed in the condenser section. 


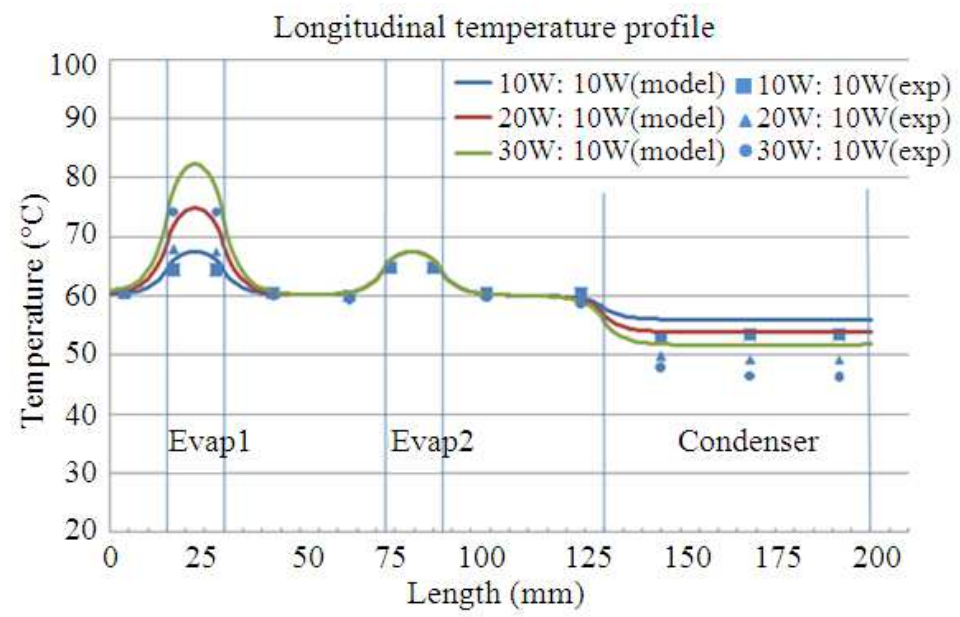

(a)

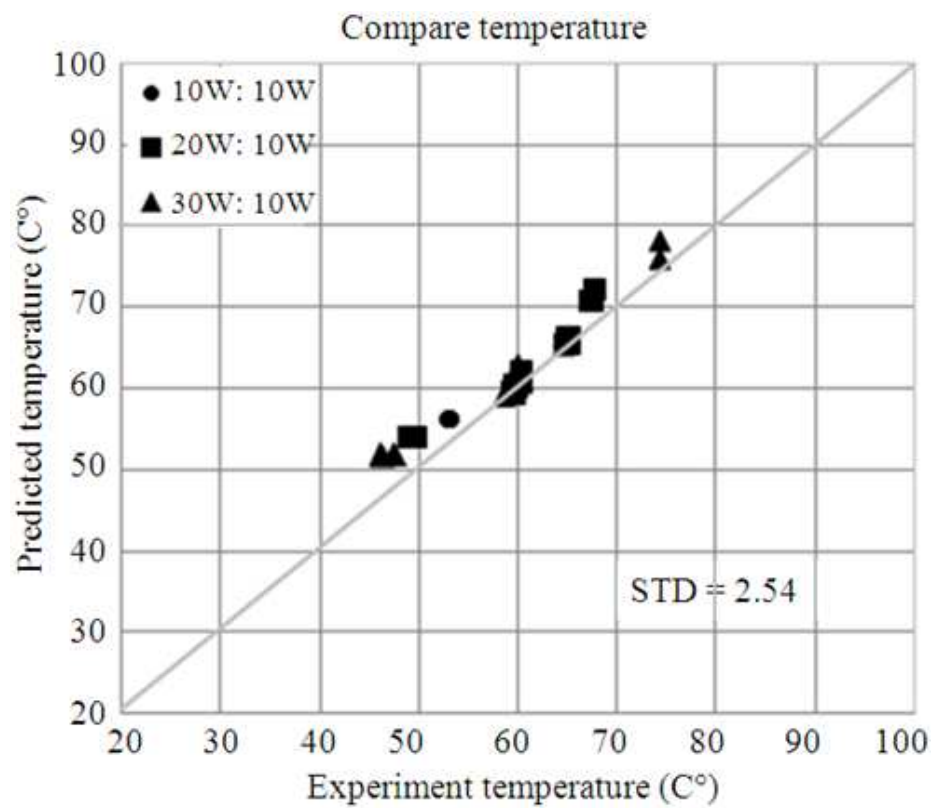

(b)

Fig. 9. Compare data between mathematical model and experimental data, (a) Mathematical and experimental result, (b) Standard deviation (STD)

This temperature difference occurred in the condenser section due to the fact that uniform heat flux (boundary condition) was applied to the mathematical model. Furthermore, thermocouples may be affected by thermal grease and contact surface.

\section{CONCLUSION}

The mathematical model using the Finite Element Method to predict temperature and thermal resistance has been established. Thermal resistances will slightly de crease from $0.589-0.53^{\circ} \mathrm{C} / \mathrm{W}$ when increasing distance between the two heat sources to $12 \mathrm{~mm}$. Then, when the distance was increased more than $12 \mathrm{~mm}$, the thermal resistance was quite constant at $0.53^{\circ} \mathrm{C} / \mathrm{W}$. It can be seen that the vapor pressure drop decreased when the distance between each heat source was increased. When the heat source was placed closer to the condenser section, the heat easily transferred to the condenser section. It caused the evaporator temperature to decrease. When the power 
input of HT1 was increased from $10 \mathrm{~W}$ to $30 \mathrm{~W}$ and HT2 was fixed at $10 \mathrm{~W}$, thermal resistance slightly increased from $0.56-0.58^{\circ} \mathrm{C} / \mathrm{W}$. The results from the mathematical model are in good agreement with the experimental data (STD $\pm 2.54 \%$ ). The trend of thermal resistance from this experiment agreed with Park (1997).

\section{ACKNOWLEDGEMENT}

This research has been supported by the strategic scholarships for frontier research network for the Ph.D. program Thai doctoral degree from office of the higher education commission, Thailand (contract number 113/2550), Fujikura (Thailand) Ltd. and Chiang Mai University.

\section{REFERENCES}

Busse, C.A. and P.C. Prenger, 1984. Numerical analysis of the vapor flow in cylindrical heat pipes. Proceedings of the 5th International Heat Pipe Conference, (PC' 84), Japan, pp: 214-219.

Chen, M.M. and A. Faghri, 1990. An analysis of the vapor flow and the heat conduction through the liquid-wick and pipe wall in a heat pipe with single or multiple heat sources. Int. J. Heat Mass Trans., 33: 1945-1955. DOI: 10.1016/00179310(90)90226-K

Faghri, A. and M. Buchko, 1991. Experimental and numerical analysis of low-temperature heat pipes with multiple heat sources. J. Heat Trans., 13: 728734. DOI: $10.1115 / 1.2910624$

Jirapol, K., 2008. Evaluation of porous material porosity for highest thermal performance in miniature heat pipe. Chaing MAI University.
Kim, K.S., M.H. Won, J.W. Kim and B.J. Back, 2003. Heat pipe cooling technology for desktop PC CPU. Applied Thermal Eng., 23: 1137-1144. DOI: 10.1016/S1359-4311(03)00044-9

Mashiko, K., V. Kumthonkittkun, H. Kuriyama, P. Ektummakii and M. Mochizuki et al., 2005. New composite wick heat pipe for cooling personal computers. Fujikura Giho., 108: 26-30.

Maziuk, V., A. Kulakov, M. Rabetsky, L. Vasiliev and M. Vukovic, 2001. Miniature heat-pipe thermal performance prediction tool-software development. Applied Thermal Eng., 21: 559-571. DOI: 10.1016/S1359-4311(00)00066-1

Park, J.H., 1997. A study on thermal performance of heat pipe for optimum placement of satellite equipment. ETRI J., 19: 59-70. DOI: 10.4218/etrij.97.0197.0023

Thuchayapong, N., A. Nakano, P. Sakulchangsatjatai and P. Terdtoon, 2012. Effect of capillary pressure on performance of a heat pipe: Numerical approach with FEM. Applied Thermal Eng., 32: 93-99. DOI: 10.1016/j.applthermaleng.2011.08.034

Vasiliev, L.L., A.A. Antukh, V.V. Maziuk, A.G. Kulakov and M.I. Rabetsky et al., 2002. Miniature heat pipe experimental analysis and software development. Proceedings of the 12th International Heat Pipe Conference, (PC' 03), Russia, pp: 329-335.

Zhu, N. and K. Vafai, 1999. Analysis of cylindrical heat pipes incorporating the effects of liquid-vapor coupling and non-Darcian transport-a closed form solution. Int. J. Heat Mass Trans., 42: 3405-3418. DOI: $10.1016 / \mathrm{S} 0017-9310(99) 00017-4$ pray 